\title{
A Randomized Controlled Trial comparing the efficacy of low-dose amitriptyline, amitriptyline with pindolol and surrogate placebo in the treatment of chronic tension-type facial pain*
}

\author{
A.M. Agius' ${ }^{1}$ N.S. Jones², R. Muscat ${ }^{3}$ \\ The Medical School, University of Malta, Msida, Malta \\ 2 Department of Otolaryngology, University of Nottingham, United Kingdom \\ ${ }^{3}$ Department of Physiology and Biochemistry, University of Malta, Msida, Malta
}

Rhinology 51: 143-153, 2013

DOI:10.4193/Rhino12.187

*Received for publication:

November 7, 2012

Accepted: February 8, 2013

\begin{abstract}
Summary
Background: Patients often present to otolaryngologists with chronic facial pain, presumed to be of sinus origin despite normal nasal endoscopy and sinus CT. This pain has increasingly been recognized as being of neurological origin with one of the common est underlying causes being mid-facial segmental tension-type pain (MFP) which is a version of tension-type headache affecting the midface.
\end{abstract}

Objectives: Primary outcome measures: 1 . To determine whether low-dose amitriptyline reduces pain scores compared to surrogate placebo in patients with chronic MFP. 2. To determine whether the addition of pindolol, a beta blocker with serotonin receptor blocking properties hastens onset of action or improves efficacy of amitriptyline. Secondary outcome measure: to determine whether amitriptyline or amitriptyline with pindolol significantly reduces analgesic consumption.

Methodology: Sixty two patients were randomized to three treatment groups (a) amitriptyline 10mg daily (b) amitriptyline 10mg daily with pindolol $5 \mathrm{mg}$ twice daily and (c) loratadine $10 \mathrm{mg}$ daily. Daily pain scores using a facial pain diary were recorded over eight weeks.

Results: At 8 weeks, pain frequency and intensity were significantly reduced in patients treated with amitriptyline and in those receiving amitriptyline with pindolol compared to surrogate placebo. Patients on the combination therapy showed significantly improved clinical outcome and significantly reduced analgesic intake compared to those on amitriptyline alone.

Conclusion: Low dose amitriptyline is effective in the management of MFP and is enhanced by the addition of pindolol.

Key words: chronic facial pain, tension-type headache, tension-type facial pain, amitriptyline, pindolol, randomized controlled study, sinus pain

\section{Introduction}

From 7,476 patients presenting to an otolaryngology clinic in Malta with nasal complaints $25 \%$ had significant facial pain involving the mid-face (personal data). Patients often interpret their facial pain as being of 'sinus' origin because of the anatomical proximity of the sinuses.

In a recent study of 305 Maltese patients satisfying the 1997 
American Academy Taskforce clinical criteria for chronic rhinosinusitis, the commonest principal presenting symptom was facial pain, but $60 \%$ of these had CT scans which were normal or showed turbinate hypertrophy ${ }^{(1)}$. It would appear that 'sinusitis' has been clinically over-diagnosed on the basis of facial pain ${ }^{(2)}$. The 2007 European Position Paper revised diagnostic criteria for rhinosinusitis to include CT and nasal endoscopic findings ${ }^{(3)}$. The 2012 update ${ }^{(4)}$ dedicated a section to the causes of facial pain that may present under the guise of chronic rhinosinusitis.

West and Jones reported on a series of 101 patients presenting with symptoms of rhinosinusitis but with normal nasal endoscopy and sinus $C T$ who responded to medical treatment for neurological diagnoses ${ }^{(5)}$. Jones went on to describe mid-facial segmental pain (MFP) ${ }^{(6)}$ as a tension-type pain of neurological origin, pressing or aching in quality with a bilateral distribution, involving the nasion, periorbital regions, cheeks or paranasal areas. MFP was frequently associated with tension-type headache, involving the frontal, parietal and occipital regions ${ }^{(7)}$.

Tension-type pain is thought to be due to sensitization of the second order neuron at the trigeminal nucleus subcaudalis, the facial equivalent of the dorsal horn of the spinal cord ${ }^{(8)}$ (Figure 1). Sessle et al. ${ }^{(9)}$ demonstrated convergence of face, head and neck afferents onto the trigeminal subnucleus caudalis explaining why headache and occipital pain often accompany tension-type facial pain ${ }^{(10)}$. Convergence may also explain why facial pain may be associated with autonomic nasal symptoms. Neurons from the trigeminal nucleus cross the midline at the trigeminal lemniscus and ascend to the contralateral thalamus which directs rostral projections to the amygdala and cortex ${ }^{(11)}$ (Figure 1).

Descending pain modulation is mediated through projections

Table 1. Diagnostic criteria of Chronic tension-type headache (International Headache Society Definition, ICHD-II, 2004).

1. Headache occurring on $\geq 15$ days per month on average for $>3$ months and fulfilling criteria 2 through 5

2. Headache lasts hours or may be continuous

3. Headache has at least two of the following characteristics: - Bilateral location

- Pressing/tightening (non-pulsating) quality

- Mild or moderate intensity

- Not aggravated by routine physical activity such as walking or climbing stairs

4. Both of the following:

- No more than one of photophobia, phonophobia, or mild nausea

- Neither moderate or severe nausea nor vomiting

5. Not attributed to another disorder from the basal ganglia, thalamus, anterior cingulate cortex and prefrontal cortex to the periaqueductal grey matter (PAG) in the midbrain ${ }^{(12)}$. The PAG communicates with the rostroventral medulla (RVM) where pain-modulating descending serotonergic and noradrenergic anti-nociceptive pathways originate ${ }^{(13)}$. Cell bodies and dendrites of serotonergic neurons in the dorsal raphe brainstem nuclei possess a concentration of presynaptic 5-HT1 A auto-receptors which play a crucial self-regulatory role in the function of the nociceptive system ${ }^{(14,15)}$.

Pindolol, a $\beta$-adrenergic antagonist, binds to the 5 -HT1 A receptor and potentiates serotonergic effects in projection areas ${ }^{(16)}$. It accelerates the onset of action of selective serotonin reuptake inhibitors (SSRI) ${ }^{(17,18)}$ and has also been used in the treatment of fibromyalgia ${ }^{(19)}$.

Jones suggested low-dose amitriptyline as effective treatment for MFP ${ }^{(6)}$. Tricylic antidepressants are known to be effective in the prophylaxis of tension-type headache and are thought to reduce the sensitivity of the second order neurone at the level of the spinal cord ${ }^{(20)}$.

In chronic tension-type headache as defined by the International Headache Society (IHS classification 2.3) patients have at least 15 headache days per month ${ }^{(21)}$ with the characteristics detailed in Table 1. The criteria for chronic MFP were extrapolated and applied from these criteria.

In patients with chronic MFP, this prospective randomized single-blind controlled clinical trial compared the outcome of patients treated with either amitriptyline $10 \mathrm{mg}$ daily, or amitriptyline $10 \mathrm{mg}$ daily with pindolol $5 \mathrm{mg}$ twice daily, against a surrogate placebo (loratadine 10mg daily). The first Null hypothesis was that amitriptyline $10 \mathrm{mg}$ daily or amitriptyline $10 \mathrm{mg}$ daily with pindolol $5 \mathrm{mg}$ twice daily, does not affect the clinical response to pain when compared to a surrogate placebo (loratadine 10mg daily). The second Null hypothesis was that the addition of pindolol, a serotonin receptor agonist, does not affect the clinical response in terms of facial pain scores to pain.

\section{Materials and methods}

\section{Patients}

A cohort of 240 consecutive patients with chronic mid-facial pain with or without tension headache for more than 15 days per month for at least three months was prospectively followed up for 36 months to determine long-term patient outcomes. Detailed results of the cohort follow-up are to be reported (personal data) and 156 of the 240 patients had chronic mid-facial tension-type pain (MFP). The process of recruitment and followup was carried out in accordance with CONSORT guidelines ${ }^{(22)}$ and a flow diagram of this parallel study is presented in Figure 2. Attention was paid to patient selection with strict application of International Headache Society criteria so as to define and 


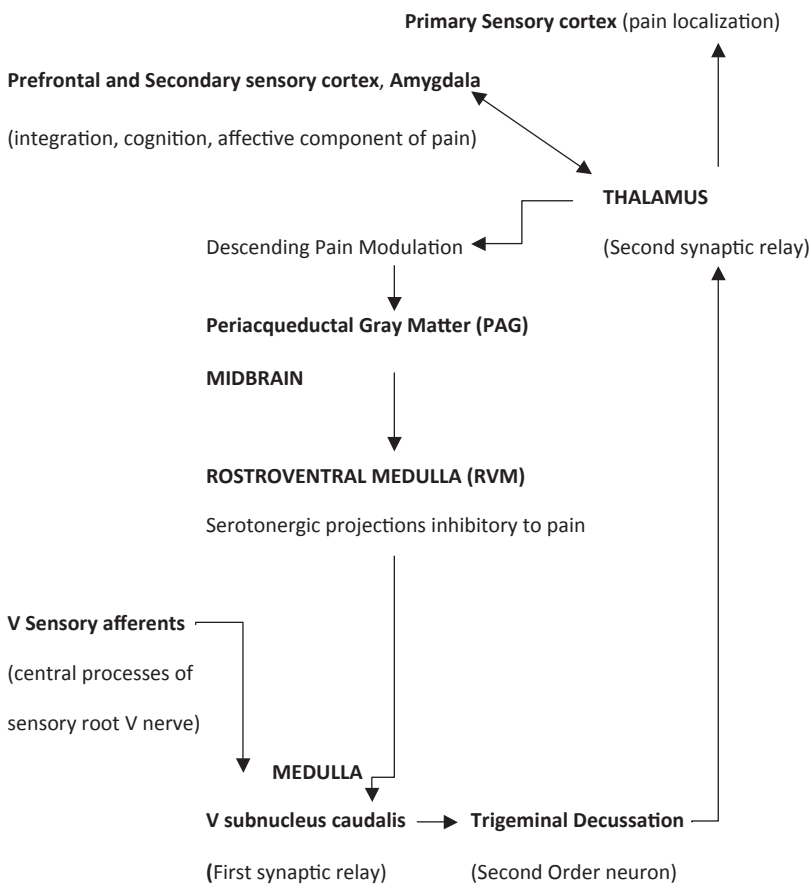

Figure 1. An outline of the facial nociceptive pathway.

differentiate tension-type pain from facial migraine without aura (Table 2). Tension-type facial pain and facial migraine became more difficult to distinguish once pain frequency increased ${ }^{(23)}$ and some patients who have a severe exacerbation of their tension type facial pain get a migrainous attack suggesting that there is an overlap between the two conditions ${ }^{(24)}$. Migraine with aura was understandably much easier to distinguish from tension-type pain than migraine without aura.

The recruitment inclusion and exclusion criteria are listed in Table 3. Only patients between 16 and 65 years old were recrui-

Table 2. Diagnostic criteria for Migraine without aura (International Headache Society Definition IHD-II, 2004).

1. At least five attacks fulfilling 2 through 5

2. Headache attacks lasting 4 to 72 hours (untreated or successfully treated)

3. Headache has at least two of the following characteristics: - Unilateral location

- Pulsating quality

- Moderate or severe pain intensity

- Aggravation by or causing avoidance of routine physical activity (such as walking or climbing stairs)

4. During headache at least one of the following

- Nausea and/or vomiting

- Photophobia and phonophobia

5. Not attributed to another disorder

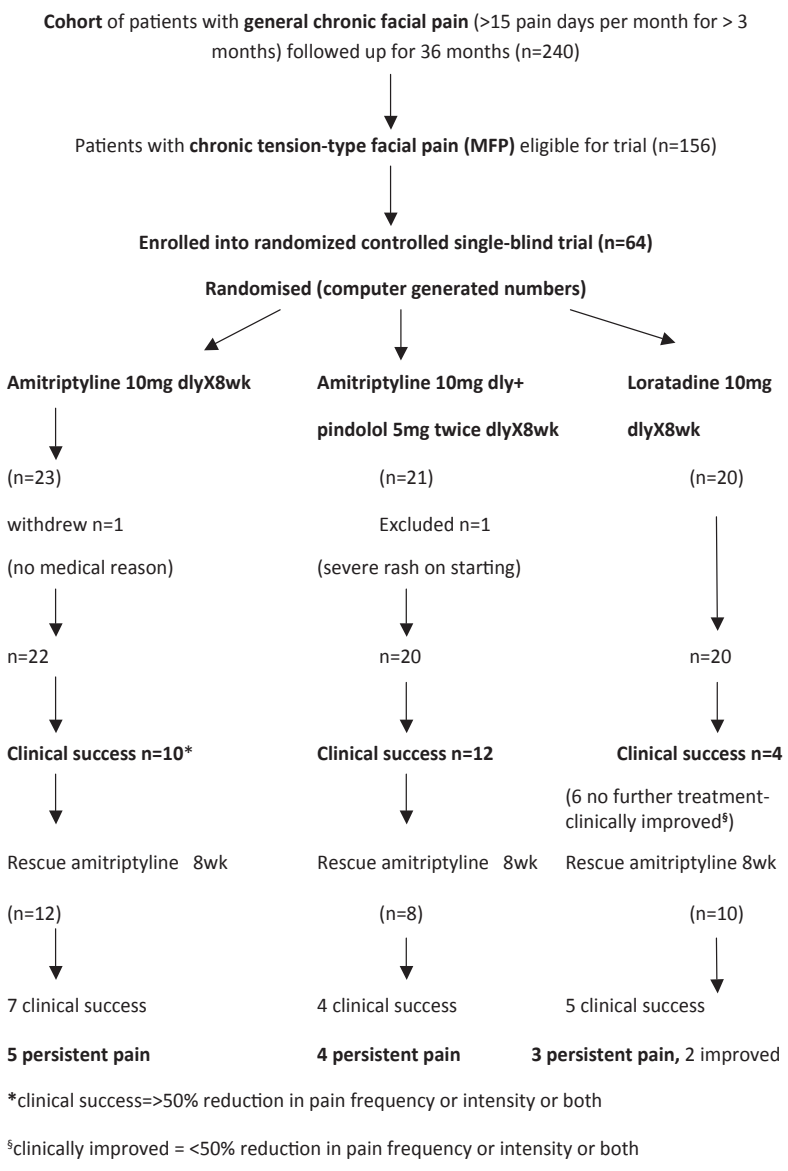

Figure 2. Flow diagram showing progress of the trial and patient outcome.

Table 3. Trial Inclusion and exclusion criteria.

\section{Trial Inclusion criteria}

- Age 16 to 65 years

- $>15$ pain days per month for $>3$ months

- Bilateral, pressing or aching pain, affecting midface but may involve head

Normal ENT examination, fundoscopy, cranial nerves, blood pressure

- Normal nasal endoscopy and CT sinuses/brain

\section{Trial Exclusion criteria}

- Symptoms of sinusitis such as rhinorrhoea, postnasal drip, hyposmia

- $\quad$ Sinus surgery within 2 years

Pregnancy

- Facial pain associated with barotrauma

Facial trauma

- Temporomandibular joint dysfunction and pain of dental origin

- Patients on antidepressants, hypnotics, beta-blockers, clopidrogel, aspirin

- More than 1 attack migraine per month

- Degenerative disease (eg, multiple sclerosis) or tumours of Central Nervous System

- Substance or alcohol abuse

Medication overuse headache

- Hamilton score $>7$ (clinical depression)

CT sinuses with mucosal thickening $>3 \mathrm{~mm}$ 
Reduction in pain frequency scores after 8 weeks in three treatment groups

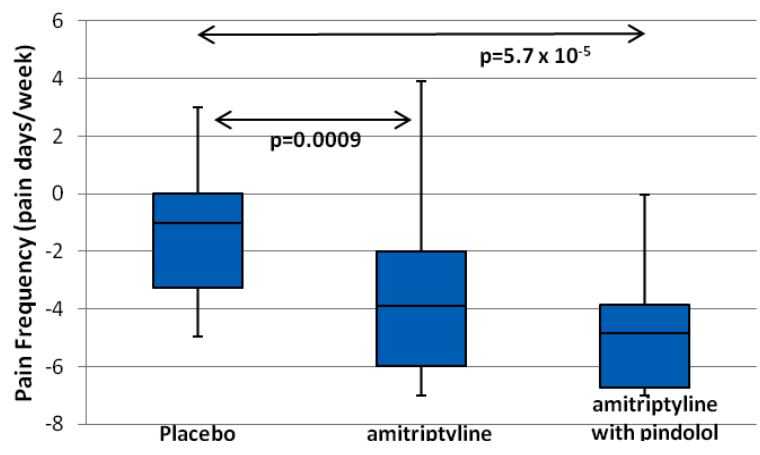

Figure 3. Reduction in pain frequency scores after 8 weeks treatment in amitriptyline, amitriptyline with pindolol and surrogate placebo groups. The box plots represent 25 th, mean and 75 th percentiles with minimum and maximum values. $P$ value is calculated using $t$ test two sample assuming unequal variances (two tailed). There is no significant difference between amitriptyline and amitriptyline with pindolol groups, $\mathrm{p}=$ 0.58 .

ted. Pregnant women, patients with facial trauma or with pain due to changes in ambient pressure (such as flying or diving) were excluded. Patients with temporomandibular dysfunction with clicking, tenderness of the temporomandibular joint, or with dental pain related to thermal sensitivity or percussion of the teeth were excluded. A standard patient history was taken as shown in Appendix 1.

Any prior surgical treatment was documented, and only patients whose sinus surgery predated the study by 2 years were allowed to participate. Patients with mixed tension-type pain with migraine were included in the study so long as they did not have more than one bout of migraine monthly, according to criteria established by previous studies on tension headache ${ }^{(25-27)}$. Patients had an ENT examination, cranial nerve examination, fundoscopy to exclude papilloedema and their blood pressure was checked. Nasal endoscopy was carried out and those patients with intranasal pus or polyps were excluded ${ }^{(28)}$. Those with oedematous mucusa were included since in previous local studies nasal mucosal oedema was a non-specific finding not associated with sinusitis ${ }^{(1,29)}$.

A computed tomogram of their brain and sinuses with coronal and axial cuts to exclude sinusitis and intracranial pathology was carried out. Computed tomography has for several years been considered the gold standard for evaluation of the paranasal sinuses ${ }^{(30)}$, especially when correlated with nasal endoscopy ${ }^{(31)}$. Patients with sinus mucosal thickening of over $3 \mathrm{~mm}$ on the CT were excluded.
Reduction in pain intensity scores after 8 weeks of treatment in three groups of patients

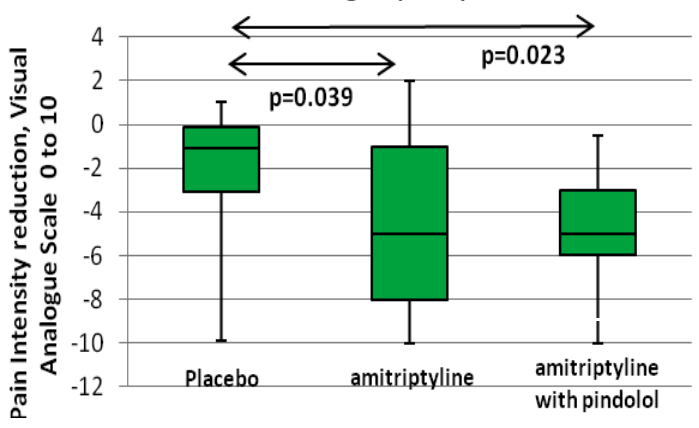

Figure 4. Box plots of reduction in pain intensity scores over 8 weeks treatment in two treatment groups and surrogate placebo. The box plots represent 25 th, mean and 75 th percentiles with minimum and maximum values. $P$ values are calculated from $t$ test two sample assuming unequal variances (two tailed). There is no significant difference between amitriptyline and amitriptyline with pindolol groups $(p=0.98)$.

Those patients with a history of psychiatric illness or those on any antidepressant, antipsychotic or hypnotic treatment were excluded since such individuals were suspected to have dysfunction of their serotonergic pathways. Indeed, headaches have been associated with depression ${ }^{(32,33)}$. The Hamilton questionnaire was used to assess mood, feelings, insomnia, attitude towards work and somatic symptoms. Only those patients scoring up to 7 were included in the clinical trial, a Hamilton score of over 20 being strongly indicative of a depressive disorder ${ }^{(34)}$.

Individuals with medication-overuse headaches were excluded as it was felt that these constituted a particular group that was difficult to treat and whose medication may have altered serotonin reuptake activity. Patients with substance or alcohol abuse were also excluded for the same reason.

Any patients with intracranial tumours or neurological degenerative disease such as multiple sclerosis were excluded. Patients were asked what analgesics they were taking and how often. The frequency and dose of analgesic was recorded throughout treatment. Some patients also complained of unsteadiness along with their facial pain and this was recorded. Since the clinical trial involved the use of tricyclic antidepressants and beta-blockers, those patients with contraindications to taking tricyclic antidepressants or beta-blockers were excluded, as were patients already on these drugs. Similarly, any patients taking drugs that alter platelet activation, such as clopidrogel, were excluded because of the effect on blood serotonin. Serial blood serotonin was analysed as part of this study but the results are not reported herein ${ }^{(35)}$. 
For the randomized controlled trial it was intended to recruit the first 90 patients with MFP from the 156 originally diagnosed in the cohort. Based on pilot data of 23 patients' pain frequency and intensity before and after eight weeks of treatment and using standard sample size estimation methods for comparing means, it was estimated that a sample of 30 patients was sufficient in each of the three groups to achieve an $\alpha=0.05$ and $\beta$ $=0.1$ (i.e., a power of $90 \%$ ) when comparing the two treatment groups to surrogate placebo ${ }^{(36)}$. An interim analysis to validate the estimated statistical power of the study revealed that, on comparing groups the results were so significant that after recruiting just over 20 patients per treatment arm it was no longer necessary to recruit more.

Patients in the clinical trial were asked to keep a baseline facial pain diary for 4 weeks to confirm that they satisfied the criteria for entry to the study. The diary method has been shown as a validated method for recording pain ${ }^{(37)}$. Patients recorded whether they had any pain (pain frequency expressed as pain days per week with score out of 7 ), its severity (using a visual analogue score 0 to $10 ; 0=$ no pain, $10=$ unbearable pain) and duration (in hours) and any analgesics taken. Other symptoms, such as nausea or dizziness, were also recorded. Patients continued to keep their diaries during the trial so that the mean frequency of pain episodes per week and the relative intensities could be calculated throughout the treatment (see Appendix 2).

Pain frequency was determined at trial entry using an average of 4 weeks pre-trial. Frequency was determined at week 3 and at week 8 . Pain intensity was recorded at trial entry and at week 8. Treatment success was defined as more than $50 \%$ reduction of pain frequency or intensity or both. This was the primary outcome measure and any reduction in pain frequency or intensity by $50 \%$ or less was considered treatment failure, even though such patients may have had score improvement. Patients showing a successful outcome in frequency may have not necessarily had a successful outcome in intensity and vice versa.

The secondary outcome measure was a reduction in analgesic consumption by patients. Treatment success in terms of analgesic use at the end of 8 weeks of treatment was defined as the consumption of less than $50 \%$ of the pre-treatment analgesic dose.

Patients were randomly assigned to one of three treatment groups (see below) on the basis of computer-generated numbers ${ }^{(38)}$ and treated for eight weeks (Figure 2).

The first group was treated with low-dose $(10 \mathrm{mg}$ ) amitriptyline at bedtime for 8 weeks. The second group was treated with $10 \mathrm{mg}$ daily amitriptyline at bedtime and pindolol $5 \mathrm{mg}$ twice daily (half the normal dose) combined for 8 weeks. The third group was treated with a surrogate placebo, loratadine $10 \mathrm{mg}$ daily at bedtime for 8 weeks. Loratadine was selected as it was a well-established antihistamine with a good safety profile, not known to have any effect upon platelet activation, as seen with the newer antihistamines such as rupatadine.

Patients were blinded as to which treatment arm they were in. They were followed up for a total of 36 months so as to determine time to recurrence (if any) of their facial pain. Patients having an unsuccessful course of surrogate placebo were allowed an 8-week 'rescue' course of low-dose amitriptyline (Figure 2). Any clinical trial patients whose pain recurred after 8 weeks were offered a one further 8-week course of low-dose amitriptyline. Patients still symptomatic after the second treatment were categorized as having 'persistent pain'.

An information sheet was supplied to the patients and the corresponding author (AA) was on hand for guidance or questions. Patients were individually consented for entry into the study and they were given the option to withdraw at any time. The study was approved by the Malta Health Ethics Committee.

\section{Statistical methods}

Statistical analyses were carried out using SPSS for Windows version 16.0. Results were presented as mean \pm SD. The normality of pre-treatment pain frequency and intensity scores in the 62 patients was confirmed using Q-Q plots. Differences in mean age of the three groups were tested using analysis of variance (ANOVA). Differences in gender between the three groups were tested using Fisher's exact test.

Comparison of change in pain scores within a group during the trial was carried out using paired t test two sample for means since they were linear measurements on the same patient. For comparison between treatment groups and surrogate placebo, mathematical differences between scores at 2 points in the trial were compared using $t$ test assuming unequal variances (twotailed).

Treatment success was defined as a greater than $50 \%$ reduction in pain frequency or intensity or both. When calculating treatment efficacy, the cut-off point between success and failure was a $>50 \%$ improvement in pain scores and for this dichotomous analysis the chi squared test was used.

\section{Results}

From sixty four patients with MFP initially recruited into the study, one patient opted to discontinue her treatment, for no medical reason. Another was withdrawn from the trial by the investigator when, 48 hours into treatment she developed a serious skin rash.

The remaining 62 patients consisted of 46 women and 16 men with a mean age of $36.6 \pm 12.2$ and $32.8 \pm 7.7$ years respecti- 
Table 4. Similar gender and age structure of the randomized treatment groups. P value * calculated using Fisher's exact test, ${ }^{\S}$ calculated using ANOVA.

$\begin{array}{lcccc} & \begin{array}{c}\text { Amitripty- } \\ \text { line }\end{array} & \begin{array}{c}\text { Amitripty- } \\ \text { line with } \\ \text { pindolol }\end{array} & \begin{array}{c}\text { Surrogate } \\ \text { Placebo }\end{array} & \text { p value } \\ \begin{array}{l}\text { Number of } \\ \text { women/total } \\ \text { patients) }\end{array} & 16 / 22 & 16 / 20 & 14 / 20 & 0.82^{*} \\ \begin{array}{l}\text { Mean age } \pm \\ \text { SD (years) }\end{array} & 34.7 \pm 12.1 & 37.4 \pm 11.1 & 34.9 \pm 10.9 & 0.71^{\S}\end{array}$

Table 5. Mean pain frequency scores (number of pain days per week \pm SD) at week 0,3 and 8 of the trial in amitriptyline, amitriptyline with pindolol and surrogate placebo groups and the statistical significance of the score reduction. * The $\mathrm{p}$ values were calculated using $\mathrm{t}$ test, paired two sample for means and compared the difference between score at Week 0 and subsequent weeks.

\begin{tabular}{|c|c|c|c|c|c|}
\hline & Week 0 & Week 3 & p value* & Week 8 & p value* \\
\hline $\begin{array}{l}\text { amitriptyline } \\
(n=22)\end{array}$ & $\begin{array}{c}5.81 \\
\pm 1.82\end{array}$ & $\begin{array}{c}2.14 \\
\pm 2.12\end{array}$ & $\begin{array}{c}2.1 \\
\times 10^{-6}\end{array}$ & $\begin{array}{c}1.85 \\
\pm 2.21 \text { * }\end{array}$ & $\begin{array}{l}8.52 \\
\times 10^{-7}\end{array}$ \\
\hline $\begin{array}{l}\text { amitriptyline } \\
\text { with pindolol } \\
(n=20)\end{array}$ & $\begin{array}{c}6.2 \\
\pm 1.28\end{array}$ & $\begin{array}{r}2.3 \\
\pm 2.62\end{array}$ & $\begin{array}{c}1.24 \\
\times 10^{-6}\end{array}$ & $\begin{array}{c}1.56 \\
\pm 2.13^{\S}\end{array}$ & $\begin{array}{c}1.51 \\
\times 10^{-8}\end{array}$ \\
\hline $\begin{array}{l}\text { Placebo } \\
(n=20)\end{array}$ & $\begin{array}{c}5.85 \\
\pm 1.63\end{array}$ & $\begin{array}{c}4.24 \\
\pm 2.39\end{array}$ & 0.008 & $\begin{array}{c}4.35 \\
\pm 2.39\end{array}$ & 0.005 \\
\hline
\end{tabular}

Table 6. Mean pain intensity scores $( \pm S D$ ) at start and end of trial for amitriptyline, amitriptyline with pindolol and surrogate placebo groups. Scores are out of $10 .{ }^{*}$ The $p$ values were calculated from $t$ test, paired two sample for means.

\begin{tabular}{|c|c|c|c|}
\hline & $\begin{array}{l}\text { Score at } \\
\text { Week } 0\end{array}$ & $\begin{array}{l}\text { Score at } \\
\text { Week } 8\end{array}$ & p value* \\
\hline $\begin{array}{l}\text { amitriptyline } \\
(n=22)\end{array}$ & $7.84 \pm 1.97$ & $3.48 \pm 2.61$ & $9.1 \times 10^{-6}$ \\
\hline $\begin{array}{l}\text { amitriptyline with } \\
\text { pindolol }(n=20)\end{array}$ & $7.85 \pm 1.86$ & $3.37 \pm 1.96$ & $3.95 \times 10^{-6}$ \\
\hline Placebo $(n=20)$ & $7.25 \pm 2.30$ & $5.05 \pm 2.91$ & 0.008 \\
\hline
\end{tabular}

vely. All patients were treated for 8 weeks. Twenty two patients received amitriptyline $10 \mathrm{mg}$ at night, 20 patients received amitriptyline $10 \mathrm{mg}$ at night with pindolol $5 \mathrm{mg}$ twice a day and 20 patients received loratadine $10 \mathrm{mg}$ daily at night as surrogate placebo. These 62 patients had been in pain prior to the study for a mean of $33 \pm 42.2$ months. Their pain typically lasted a few hours per day. It was described as bilateral pressing pain oc-
Table 7. Reduction in mean pain frequency (number of pain days per week \pm SD) at week 3 and week 8 of treatment in amitriptyline, amitriptyline with pindolol and surrogate placebo groups with levels of statistical significance compared to placebo. * P was calculated using t test two sample assuming unequal variances (two tailed).

\begin{tabular}{|lcccc|}
\hline & $\begin{array}{c}\text { Frequency } \\
\text { reduction } \\
\text { by week 3 }\end{array}$ & $\begin{array}{c}\text { P value* } \\
\text { (compared } \\
\text { to Placebo) }\end{array}$ & $\begin{array}{c}\text { Frequency } \\
\text { reduction } \\
\text { by week 8 }\end{array}$ & $\begin{array}{c}\text { P value* } \\
\text { (compared } \\
\text { to Placebo) }\end{array}$ \\
\hline $\begin{array}{l}\text { amitriptyline } \\
(n=22)\end{array}$ & -3.67 & 0.012 & -3.96 & 0.0009 \\
amitriptyline & -3.67 & & \pm 2.58 & \\
$\begin{array}{l}\text { with pindolol } \\
(n=20)\end{array}$ & \pm 2.50 & 0.0057 & -4.65 & 4.35 \\
& -1.61 & & \pm 2.21 & $\times 10^{-5}$ \\
Placebo $(n=20)$ & \pm 2.44 & - & -1.50 & - \\
& & & \pm 2.09 & - \\
\hline
\end{tabular}

Table 8. Reduction in pain intensity scores (out of scale of $10 \pm$ SD) at week 8 of treatment in the amitriptyline, amitriptyline with pindolol and surrogate placebo groups with levels of statistical significance compared to control. *P was calculated using t test two sample assuming unequal variances (two tailed).

\begin{tabular}{|c|c|c|}
\hline & $\begin{array}{c}\text { Reduction in } \\
\text { Intensity score at } \\
\text { week } 8\end{array}$ & $\begin{array}{c}\text { P value* } \\
\text { (compared to } \\
\text { Placebo) }\end{array}$ \\
\hline amitriptyline $(n=22)$ & $-4.41 \pm 3.52$ & 0.039 \\
\hline $\begin{array}{l}\text { amitriptyline with } \\
\text { pindolol }(n=20)\end{array}$ & $-4.42 \pm 2.35$ & 0.023 \\
\hline Placebo $(n=20)$ & $-2.15 \pm 3.34$ & - \\
\hline
\end{tabular}

curring in the nasion, cheek or periorbital areas with additional involvement of the frontal, occipital or parietal regions. Most patients had simultaneous pain in two to four areas and 167 sites of pain were described by 62 patients: the nasion [46] with frontal [43] areas were more commonly involved, followed by bilateral periorbital [33], bilateral cheek [25], bi- parietal [11] and occipital [9] regions.

Q-Q plots confirmed the normality of pre-treatment pain and intensity scores in the 62 patients. Mean age and gender in the three treatment groups did not differ significantly (Table 4). Pain frequency scores in amitriptyline, amitriptyline with pindolol and surrogate placebo groups were all significantly reduced at week 3 and week 8 of the trial (Table 5). Pain frequency in amitriptyline and amitriptyline with pindolol groups continued decreasing from week 3 to week 8 while in the surrogate placebo group there was no further reduction after week 3. Pain intensity scores in amitriptyline, amitriptyline with pindolol and surrogate placebo groups were all significantly reduced at week 
Table 9. Clinical success in reducing pain frequency by $>50 \%$ at Week 3 of treatment. *P value was calculated using chi squared test.

\begin{tabular}{|c|c|c|c|}
\hline & Success & Failure & $\begin{array}{c}\text { P value* } \\
\text { (compared to } \\
\text { Placebo) }\end{array}$ \\
\hline $\begin{array}{l}\text { amitriptyline } \\
(n=22)\end{array}$ & 16 & 6 & 0.0154 \\
\hline $\begin{array}{l}\text { amitriptyline with } \\
\text { pindolol }(n=20)\end{array}$ & 16 & 4 & 0.0046 \\
\hline Placebo $(n=20)$ & 6 & 14 & - \\
\hline
\end{tabular}

Table 10. Clinical success in reducing pain frequency $>50 \%$ at Week 8 of treatment. ${ }^{*}$ P value was calculated using chi squared test.

\begin{tabular}{|c|c|c|c|}
\hline & Success & Failure & $\begin{array}{c}\text { P value* } \\
\text { (compared to } \\
\text { Placebo) }\end{array}$ \\
\hline $\begin{array}{l}\text { amitriptyline } \\
(n=22)\end{array}$ & 18 & 4 & 0.0028 \\
\hline $\begin{array}{l}\text { amitriptyline with } \\
\text { pindolol }(n=20)\end{array}$ & 18 & 2 & 0.00001 \\
\hline Placebo $(n=20)$ & 6 & 14 & - \\
\hline
\end{tabular}

Table 11 . Clinical success in reducing pain intensity by $>50 \%$ by Week 8 of treatment. *P value was calculated using chi squared test.

\begin{tabular}{|c|c|c|c|}
\hline & Success & Failure & $\begin{array}{c}\text { P value* } \\
\text { (compared to } \\
\text { Placebo) }\end{array}$ \\
\hline $\begin{array}{l}\text { amitriptyline } \\
(n=22)\end{array}$ & 12 & 10 & 0.048 \\
\hline $\begin{array}{l}\text { amitriptyline with } \\
\text { pindolol }(n=20)\end{array}$ & 15 & 5 & 0.0021 \\
\hline Placebo $(n=20)$ & 4 & 16 & - \\
\hline
\end{tabular}

8 (Table 6).

To compare pain frequency between the treatment and surrogate placebo groups, the pain frequency at the beginning of treatment was subtracted from the pain frequency at week 3 and at week 8 of treatment. The mathematical difference was used to compare active treatment and surrogate placebo groups using a two-sample t test assuming unequal variances. Pain intensity was similarly compared by subtracting the value at the end of treatment from the initial value (Tables 7 and 8 ). The differences between active treatment groups and surrogate placebo were highly significant and showed that pain frequency already started to decrease significantly with amitriptyline or amitriptyline with pindolol by the third week of treatment. The reduction in intensity score seen by the end of treatment, although signi-
Table 12. The number and proportion of patients not having any analgesics at the start and end of the trial. ${ }^{*}$ The $p$ value was calculated using the chi squared test.

\begin{tabular}{|lccc|}
\hline & $\begin{array}{c}\text { Number (and } \\
\text { percentage) } \\
\text { of patients } \\
\text { not having } \\
\text { analgesics at } \\
\text { start of trial }\end{array}$ & $\begin{array}{c}\text { Number (and } \\
\text { percentage) } \\
\text { of patients } \\
\text { not having } \\
\text { analgesics at } \\
\text { end of trial }\end{array}$ & $\begin{array}{c}\text { P value* } \\
\text { (compared to } \\
\text { Placebo) }\end{array}$ \\
\hline $\begin{array}{l}\text { amitriptyline } \\
(n=22)\end{array}$ & $1(4.5 \%)$ & $13(59 \%)$ & 0.0089 \\
$\begin{array}{l}\text { amitriptyline with } \\
\text { pindolol ( } n=20)\end{array}$ & $1(5 \%)$ & $14(70 \%)$ & 0.0098 \\
\hline Placebo $(n=20)$ & $2(10 \%)$ & $8(40 \%)$ & - \\
\hline
\end{tabular}

Table 13. Resolution of dizziness symptoms in the three treatment groups.

\begin{tabular}{|c|c|c|}
\hline & $\begin{array}{l}\text { patients with } \\
\text { dizziness before trial }\end{array}$ & $\begin{array}{c}\text { Number resolved } \\
\text { after trial }\end{array}$ \\
\hline $\begin{array}{l}\text { amitriptyline } \\
(\mathrm{n}=22)\end{array}$ & 10 & 10 \\
\hline $\begin{array}{l}\text { amitriptyline with } \\
\text { pindolol }(n=20)\end{array}$ & 8 & 8 \\
\hline Placebo $(n=20)$ & 5 & 1 \\
\hline
\end{tabular}

ficant, showed a degree of variation that is explained by the subjectivity of pain perception.

Box plots of the decrease in pain frequency and intensity by week 8 compared to surrogate placebo are shown in Fig. 3 and 4 , with the boxes denoting 25 th percentile, median and 75th percentile while minimum and maximum values are also shown. By week 3 of treatment, both amitriptyline and amitriptyline with pindolol were significantly successful in clinically reducing pain frequency by $>50 \%$ compared to surrogate placebo (Table 9). This reduction was maintained till week 8 by which time the amitriptyline/pindolol combination became more effective than amitriptyline alone (chi squared test, $p=0.00001$ vs 0.0028 ) (Table 10).

At week 8, amitriptyline and amitriptyline with pindolol were both clinically successful in significantly reducing pain intensity compared to surrogate placebo. The combination was much more effective than amitriptyline on its own (chi squared test, $p=0.0021$ and $p=0.048$ respectively) (Table 11 ).

Patients with clinical success had a decrease in pain frequency or intensity scores by $>50 \%$ or both. Thus the number of patients with successful outcome in Tables 10 and 11 may not be 
the same.

The secondary outcome of the study with respect to analgesic consumption showed that both amitriptyline and amitripyline with pindolol were significantly more effective than surrogate placebo in increasing the proportion of patients not using any analgesics (Table 12). The proportion of patients whose analgesic consumption reduced by more than half was $17 / 22$ (77\%) in the amitriptyline group, 19/20 (95\%) in the amitriptyline with pindolol group, and 10/20 (50\%) in the surrogate placebo group. The combination treatment was significantly more effective in reducing analgesic consumption compared to surrogate placebo ( $p=0.038$, chi squared test).

Patients with chronic MFP frequently describe dizziness as one of their symptoms. Dizziness was present in 23 of the 62 patients. The symptom disappeared completely, usually within a week, in patients receiving amitriptyline or amitriptyline with pindolol but persisted in the surrogate placebo group (Table 13).

Patients were followed up for a total of 36 months.

After surrogate placebo treatment, 10 of 20 patients did not ask for further therapy. Although these 10 all felt better, only 4 had a $>50 \%$ reduction in their frequency or intensity pain scores that could be classed as 'treatment success'. The other 10 surrogate placebo patients with more severe symptoms were offered an 8 week'rescue' course of low-dose amitriptyline following the clinical trial: 5 acquired 'treatment success', 2 were slightly better and 3 remained with persistent pain (Figure 2).

In the amitriptyline group, 10 of 22 patients responded successfully to the 8 week course. The remaining 12 required a second 'rescue' course of treatment for continued pain: in 7 this resolved but 5 continued to exhibit persistent pain.

In the amitriptyline with pindolol group, 12 patients of a total of 20 responded after 8 weeks. The remaining 8 required a second 'rescue' course of amitriptyline for continued pain: 4 responded and 4 continued to exhibit persistent pain (Figure 2).

About half of patients with chronic MFP having active treatment therefore responded fully within 8 weeks while one third needed another 8 weeks of low-dose amitriptyline for treatment success. The remaining 12 out of 62 patients or $19 \%$ had persistent pain that was subsequently managed by prolonged low-dose amitriptyline medication, up to 1 year.

Patients with persistent pain were identical to the original group in age and gender but their length of history of pain was 71.4 \pm 130.7 months compared to the general group of facial pain patients where it was $33.0 \pm 42.2$ months. This implied that patients whose pain persisted despite adequate treatment tended to develop their symptoms earlier on in life.

One patient on amitripyline developed a transient unsteadiness; this resolved spontaneously within the first week of treatment and the patient continued the trial. One patient taking the amitriptyline with pindolol combination developed a severe skin rash after 2 days-she was treated with oral steroids, the treatment discontinued and the patient was withdrawn from the trial.

\section{Discussion}

Patients with chronic facial pain in spite of normal CT and normal nasal endoscopy are frequent and challenging visitors to rhinology clinics. They have often believed or have been told that their symptoms are due to their 'sinus condition'. Typically at presentation to the specialist an individual may have already visited a mean of 4 physicians and may already have had surgery (39). In studies that followed up patients after sinus surgery, their pain either persisted or quickly recurred ${ }^{(40,41)}$.

Most of our patients were women in their fourth decade. Daudia and Jones ${ }^{(42)}$ studied 409 patients with facial pain presenting to their rhinology clinic in the United Kingdom and two thirds were female. In epidemiological studies of chronic tension-type headache the female to male ratio has been similarly quoted as 2:1 ${ }^{(43,44)}$. Women with tension headache have increased muscle tension compared to men at the same headache activity ${ }^{(45)}$ and women rate pain at a significantly higher level compared to men when muscle and skin of the head is stimulated electrically ${ }^{(46)}$.

Otolaryngologists may often be pressured by such patients to operate in the hope that their pain would resolve. The clinician's resistance to the surgical option may cause disappointment and patients often default from follow-up. In our clinical experience, facial pain patients become discouraged since their symptoms do not respond to conventional decongestants, antibiotics or topical intranasal steroids, or else rapidly recur after transient improvement. Analgesics seem to have a minimal effect, except for non-steroidal anti-inflammatories ${ }^{(6)}$. A lacuna of knowledge surrounds the treatment and natural course of chronic tensiontype facial pain.

It is important at an early stage to identify and differentiate tension-type facial pain and facial migraine. These are the two commonest causes of chronic facial pain and their medical treatment is different. In clinical practice, adequate follow-up with respect to their response to medical treatment may be needed in order to make the correct diagnosis ${ }^{(47)}$ and treatment may have to be modified in order to obtain a satisfactory response. In this study, patients completed a pain diary for four weeks before entry into the trial, fulfilling adequate criteria for precise diagnosis.

This study was, to our knowledge, the first clinical trial comparing treatments in chronic mid-facial segmental pain (MFP). Its findings strongly supported anecdotal evidence and clinical experience where chronic MFP has been successfully treated with low-dose amitriptyline ${ }^{(6)}$. Amitriptyline has been success- 
fully used in the prophylaxis of chronic tension-type headache for some decades ${ }^{(48)}$ and low doses have been found to be even more effective for pain as opposed to the higher doses used for treatment of depression ${ }^{(49)}$. The European Federation of Neurological Societies (EFNS) guidelines on the prophylaxis of chronic tension-type headache currently recommend amitriptyline as drug of first choice ${ }^{(50)}$.

In both the amitriptyline and amitriptyline with pindolol groups, there was a quick onset of action, significantly reducing pain frequency by the third week of treatment. This finding was surprising, since, based on its effect as an antidepressant the onset of action of low-dose amitriptyline was expected to take at least six weeks. The antidepressant action of tricyclic antidepressants is thought to be related to their central blocking effect on serotonin re-uptake ${ }^{(51)}$. The efficacy of amitriptyline in our study not only supported the concept of MFP as a tension-type pain but also implied that this drug's mode of action was peripheral rather than central. In line with current thought, amitriptyline would have therefore acted at the nucleus subcaudalis of the trigeminal nucleus in the brainstem where peripheral affective nociceptive fibres relay onto ascending pathways ${ }^{(52)}$. Descending serotonergic, noradrenergic and endogenous opioid systems would, at this site, be able to modulate ascending nociceptive impulses ${ }^{(53,54)}$.

The addition of pindolol did not hasten the onset of action of amitriptyline as initially hypothesised, but it improved statistical outcomes in terms of reduction in pain frequency and intensity scores and in reducing analgesic consumption compared to the group using amitriptyline alone.

It was likely that pindolol acted centrally where its 5-HT1 A receptor blocking action served to attenuate the auto-inhibitor negative feedback loop seen in brainstem serotonergic neurons, with a resulting increase in serotonin release in projection areas including the dorsal horn of the spinal cord or its equivalent, the trigeminal nucleus. This caused an inhibitory effect on peripheral pain, and a decrease in pain frequency or intensity. This effect of pindolol supported the current theory of pain modulation by descending serotonergic pathways ${ }^{(54,55)}$. In an alternative mode of action, pindolol has also been shown to block 5-HT1B receptors at presynaptic terminals, in this way reducing the activity of the 5-HT transporter, reducing serotonin re-uptake and increasing synaptic serotonin concentrations ${ }^{(56)}$.

The significant placebo effect observed was fairly typical of pain studies where varied temporal patterns of pain intensity have had to be taken into account. Pain scores in the surrogate placebo group decreased significantly, with half the patients reducing their analgesic doses by over $50 \%$. McQuay et al. looked at pain scores in 5 randomized controlled trials and found that up to $37 \%$ of patients obtained $>50 \%$ relief from their pain by a placebo effect ${ }^{(57)}$.

Advantages for pain treatment using low dose amitriptyline included good efficacy, cost-effectiveness and the lack of side effects seen when higher doses are prescribed. Only one patient complained of mouth dryness. From our experience, an explanation to patients that the antidepressant worked as an analgesic at a fraction of the normal dose increased compliance. Pindolol was similarly cheap, with few side effects observed in this study. However one had to bear in mind the contra-indications of beta-blockers such as asthma even though the dose used was only half the normal adult dose.

A limitation of the trial was that it was not double-blind. Patients with tension headache have been shown to have an increased risk of depression compared to healthy controls ${ }^{(32,33)}$. Our use of the Hamilton score was designed to eliminate clinically depressed patients from the study and meant that the trial focused on people with pain but without mood disorders. Future longitudinal studies may investigate the proportion of patients with tension-type facial pain that eventually goes on to develop mood disorders.

\section{Conclusion}

The first Null hypothesis was that amitriptyline $10 \mathrm{mg}$ daily or amitriptyline $10 \mathrm{mg}$ daily with pindolol $5 \mathrm{mg}$ twice daily, does not affect the clinical response to pain when compared to a surrogate placebo (loratadine 10mg daily). The second Null hypothesis was that the addition of pindolol, a serotonin receptor agonist, does not affect the clinical response in terms of facial pain scores to pain.

Both null hypotheses were therefore disproved.

An 8 week course of low-dose amitriptyline was clinically effective at significantly reducing pain frequency and intensity in patients with chronic tension-type facial pain compared to surrogate placebo. Low-dose amitriptyline combined with lowdose pindolol significantly reduced pain frequency and intensity even further, with a significant reduction of analgesic consumption. The reduction in pain frequency became apparent in both treatment groups at the third week of treatment.

\section{Acknowledgement}

Partial funding of this work was provided from the Malta Government Scholarship Scheme and Dean's fund from Faculty of Medicine and Surgery, University of Malta. Dr Neville Calleja, Head of Department of Medical Statistics, Department of Health, Malta kindly assisted with the clinical analyses. The authors are especially grateful to all the patients who kindly consented to taking part in this study. 


\section{Authorship contribution}

AMA: original concept of study and main author who carried
out the study; NJS: contribution to concept and study design;
RM: supervised trial and contributed to study design.

\section{Conflict of interest}

The authors do not have any conflicts of interest to declare.

\section{References}

1. Agius AM. Chronic sinusitis in Maltacorrelation between symptoms and CT scan. Rhinology 2010; 48: 59-64.

2. Kieff DA, Busaba NY. Negative predictive value of normal nasal endoscopy for sinus disease as a cause of isolated facial pain. J Laryngol Otol. 2011, 125: 1038-1041.

3. Fokkens WJ, Lund VJ, Mullol J, et al. European Position Paper on Rhinosinusitis and Nasal Polyps 2007; Rhinology 45 (Suppl 20): 1-139.

4. Fokkens WJ, Lund VJ, Mullol J, et al. European Position Paper on Rhinosinusitis and Nasal Polyps 2012; Rhinology 50 (Supp 23): 1-298.

5. West B, Jones NS. Endoscopy-negative, computed tomography-negative facial pain in a nasal clinic. Laryngoscope. 2001; 111 581-586.

6. Jones NS. Midfacial segmental pain:implications for rhinitis and sinusitis. Curr All Asthma Rep. 2004; 4: 187-192.

7. Jones NS. Midfacial Segment Pain: Implications for rhinitis and rhinosinusitis. Clin Allergy Immunol. 2007; 19: 323-333.

8. Bendtsen L. Sensitisation: its role in primary headache. Curr Opin Invest Drugs 2001; 3 : 449-453.

9. Sessle BJ, Hu JW, Amano N, et al. Convergence of cutaneous, tooth pulp, vis ceral, neck and muscle afferents onto nociceptive and non-nociceptive neurons in trigeminal subnucleus caudalis (medullary dorsal horn) and its implications for referred pain. Pain 1986; 27: 219-235.

10. Bartsch T, Goadsby PJ. Increased responses in trigeminocervical nociceptive neurons to cervical input after stimulation of the dura mater. Brain 2003; 1126: 1801-1813.

11. Neugebauer V, Galhardo V, Maione S et al. Forebrain pain mechanisms. Brain Res Rev. 2009; 60: 226-242.

12. Fields HL, Basbaum Al, Heinrich MM. Centra nervous system mechanisms of pain modulation. In: McMahon S, Koltzenburg M, eds. Textbook of Pain. 5th ed. Burlington, Massachusetts, USA: Elsevier Health Sciences, 2005: 125-142.

13. Fields $\mathrm{HI}$, Anderson SD, Clanton CH, Basbaum Al. Nucleus Raphe magnus: a common mediator of opiate- and stimulusproduced analgesia. Trans Am Neurol Assoc 1976; 101: 208-210

14. Miquel MC, Doucet E, Boni C, et al. Central serotonin $1 \mathrm{~A}$ receptors: respective distributions of encoding $\mathrm{mRNA}$, receptor protein and binding sites by in situ hybridization histochemistry, radioimmunohistochemistry and autoradiographic mapping in the rat brain. Neurochem Int. 1991; 19: 453-465.

15. Kia HK, Brisorgueil MJ, Daval G, et al Serotonin 5-HT1A receptors expressed by a subpopulation of cholinergic neurons in the rat medial septum and diagonal band of Broca-a double immunocytochemica study. Neuroscience 1996; 74: 143-154.

16. Clifford EM, Gartside SE, Umbers V, et al Electrophysiological and neurochemical evidence that pindolol has agonist properties at the 5-HT1A autoreceptor in vivo. $\mathrm{Br}$ Pharmacol. 1998; 124: 206-212.

17. Artigas F, Perez V, Alvarez E. Pindolol induces a rapid improvement of depressed patients treated with serotonin reuptake inhibitors. Arch Gen Psychol. 1994; 51: 248 251.

18. Blier P, Bergeron R. Effectiveness of pindolol with selected antidepressant drugs in the treatment of major depression. J Clin Psychopharmacol. 1995; 15: 217-222.

19. Wood PB, Kablinger AS, Caldito GS. Open trial of pindolol in the treatment of fibromyalgia. Ann Pharmacother. 2005; 39: 1812 1816.

20. Bendtsen $L$, Jensen $R$, Olesen J. A nonselective (amitriptyline) but not a selective (citalopram) serotonin reuptake inhibitor is effective in the prophylactic treatment of chronic tension-type headache. J Neurol Neuorsurg Psychiatry. 1996; 61: 285-290.

21. Headache Classification Committee of the International Headache Society. The International Classification of Headache disorders 2nd Edition. Cephalalgia 2004, 24 (Suppl 1): 9-160.

22. Moher D, Hopewell S, Schulz KF, et al. CONSORT 2010 explanation and elaboration: updated guidelines for reporting parallel group randomized trials. BMJ 2010; 340: c869.

23. Silberstein SD, Lipton RB, Solomon S, et al Classification of daily and near-daily headaches: proposed revision to IHS criteria. Headache 1994; 34: 1-7.

24. Solomon S, Lipton RB, Newman LC. Clinical features of chronic daily headache. Headache. 1992b; 32: 325-329.

25. Jensen R, Hindberg I. Plasma serotonin increase during episodes of tension-type headache. Cephalalgia 1994; 14: 219-222.

26. Bendtsen L, Jensen R. Hindberg I, et al. Serotonin metabolism in chronic tensiontype headache. Cephalalgia 1997; 17: 843848.

27. Bendtsen L, Mellerup ET. The platelet serotonin transport in primary headaches. Eur J Neurol. 1998; 5: 277-282.

28. Hellings PW, Scadding G, Alobid I, et al Executive summary of European Task Force document on diagnostic tools in rhinology Rhinology 2012; 50: 339-352.

29. Agius AM. Long-term follow-up of patients with facial pain in chronic rhinosinusitiscorrelation with nasal endoscopy and CT. Rhinology. 2010; 48: 65-70.

30. Zinreich SJ. Rhinosinusitis: radiologic diagnosis. Otolaryngol Head Neck Surg. 1997; 117 (Suppl): S27-34.

31. Kuhn FA. Role of endoscopy in the management of chronic rhinosinusitis. Ann Otol Rhinol Laryngol. 2004; 193(Suppl): 15-18.

32. Delgado PL. Serotonin nor-adrenaline reuptake inhibitors: New hope for the treatment of chronic pain. Int J Psych Clin Prac. 2006; 10: 16-21

33. Yucel B, Kora K, Ozyalcin, S et al. Depression, automatic thoughts, alexithymia and assertiveness in patients with tension-type headache. Headache 2002; 42: 194-199.

34. Hamilton M. A rating scale for depression. J Neurol Neurosurg Psychiatry. 1960; 23 : 56-62.

35. Agius AM, Muscat R, Jones NS. Serial blood serotonin levels in a randomized controlled trial comparing the efficacy of low-dose amitriptyline, amitriptyline with pindolol and placebo in patients with chronic tension-type facial pain (in preparation)

36. Piface, http://www.cs.uiowa.edu/ rlenth/ Power/

37. Tassorelli C, Sances G, Allena M, et al. The usefulness and applicability of a basic headache diary before first consultation: results of a pilot study conducted in two centres. Cephalalgia 2008; 28, 1023-1030.

38. http://stattrek.com/Tables/Random.aspx

39. Eross E, Dodick D, Eross M. The sinus allergy and migraine study (SAMS). Headache 2007: 47: 213-224.

40. Abu-Bakra M, Jones NS. The prevalence of nasal contact points in a population with facial pain and a control population. J Laryngol Otol. 2001; 115: 629-632.

41. Tarabichi M. Characteristics of sinus-related pain. Otolaryngol Head Neck Surg. 2000; 122: 842-847.

42. Daudia AT, Jones NS. Facial migraine in a rhinological setting. Clin Otolaryngol. 2002; 27: 521-525.

43. Boardman HF, Thomas E, Croft PR, et al. Epidemiology of headache in an English District. Cephalalgia 2003; 23: 129-137.

44. Schwartz BS, Stewart WF, Simon D, et al. Epidemiology of tension-type headache. JAMA 1998; 279: 381-383.

45. Lipchik GL, Holroyd KA, O'Donnell FJ, et al. Exteroceptive suppression periods and pericranial muscle tenderness in chronic tension-type headaches: effects of psy- 
chopathology, chronicity and disability Cephalalgia 2000; 20: 638-646.

46. Ashina S, Bendtsen L, Ashina M, et al. Generalized hyperalgesia in patients with chronic tension-type headache. Cephalalgia 2006; 26: 940-948

47. Olesen J, Dodick DW. The history and examination of headache patients. In: Olesen J Goadsby PJ, Ramadan NM et al, Eds. The Headaches 3rd Ed, Lippincott, Philadelphia USA, 2006 Chap 6 p 49.

48. Lance JW, Curran DA. Treatment of chronic tension headache. Lancet 1964; 1(7345): 1236-1239.

49. Diamond S, Baltes BJ. Chronic tension headache-treated with amitriptyline-a double blind study. Headache 1971; 11: 110-116.

50. Attal N, Cruccu G, Baron R, et al. EFNS guidelines on the pharmacological treatment of neuropathic pain: 2010 revision Eur J Neurol. 2010; 17: 1113-1123. (http:// www.efns.org/fileadmin/user_upload/guidline_papers/EFNS guideline_2010_pharma._treatment_of_neuropathic_pain.pdf)
51. Hollister, LE. Tricyclic antidepressants. N Eng J Med. 1978, 299: 1106-1109.

52. Ashina S, Bendtsen L, Jensen R. Analgesic effect of amitriptyline in chronic tensiontype headache is not directly related to serotonin reuptake inhibition. Pain 2004; 108: 108-114.

53. Brown RS, Bottomley WK. The Utilization and mechanism of action of tricyclic antidepressants in the treatment of chronic facial pain: a review of the literature. Anaes Prog. 1990; 37: 223-229.

54. Sharav $Y$, Singer $E$, Schmidt $E$, et al. The analgesic effect of amitriptyline on chronic facial pain. Pain 1987; 31: 199-209.

55. Maizels M, McCarberg B. Antidepressants and antiepileptic drugs for chronic noncancer pain. Am Family Physician 2005: 71(3): 483-490.

56. Frazer A, Daws LC. Serotonin transporter function in vivo: assessment by chronoamperometry. Ann NY Acad Sci. 1998; 861, 217-229.

57. McQuay H, Carroll D, Moore A. Variation in the placebo effect in randomised controlled trials of analgesics: all is as blind as it seems. Pain 1996; 64: 331-335.

\section{Appendix 1. Structured Clinical Interview for facial pain and follow-up.}

- Length of history:

- Site: periorbital, paranasal, cheeks, frontal, vertex, occipital, temporal-unilateral, bilateral

- Quality: pressing, aching, throbbing

- Duration, frequency and intensity

- Presence of: photophobia, nausea, vomiting

- Presence of: cough, fever, halitosis, toothache, ear pressure, fatigue, hyposmia

- Past history of migraine, family history of migraine

- Past history of systemic illness (such as lung disease)

- Details of past of nasal surgery

- $\quad$ Cigarette smoke exposure, skin test positivity

- $\quad$ Analgesic use -type and dose

- BMI, level of education, occupation/income

- Final Diagnosis

- Signs on nasal endoscopy: normal, pus, polyps, mucosal oedema

- CT results: normal, rhinitis, sinusitis, anatomical abnormality

- Treatment given

- Treatment modified

- Outcome/follow-up

\section{Appendix 2. Facial pain diary.}

Mr Adrian Mark Agius

'Desert Rose'

Triq it-Tomna

Ibragg SW 2380

Malta

Email aagius@stannesclinic.com
Name.

Tel no

Email Diary End date..

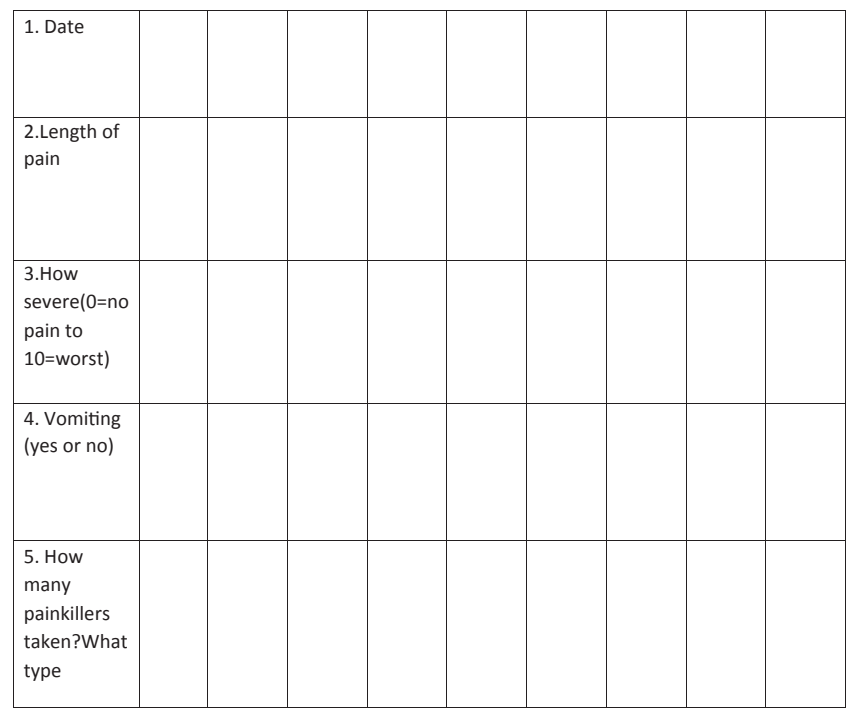

